\title{
Video-Assisted Thyroidectomy Using a Surgical Energy Device: Initial Experience in a Japanese Single-Center Cohort
}

\author{
Jun-ichi Ohkubo Tetsuro Wakasugi Shoko Takeuchi Shoichi Hasegawa \\ Azusa Takahashi Hideaki Suzuki
}

Department of Otorhinolaryngology-Head and Neck Surgery, School of Medicine, University of Occupational and

Environmental Health, Kitakyushu, Japan

\section{Keywords}

Video-assisted thyroidectomy · Microwave energy devices

\begin{abstract}
Objective: Video-assisted thyroidectomy (VAT) was approved for coverage under the Japanese public health insurance system in 2016. In our department, we introduced VAT in 2018, and we have since been performing the procedure with the assistance of surgical energy devices. We herein summarize our cases undergoing VAT, including a review of points to consider when introducing the procedure, and characteristics of the surgical energy devices. Methods: We enrolled 24 patients (14 women and 10 men; age: 24-83 years; mean: 59.0 years) with thyroid/parathyroid tumors who underwent VAT between January 2018 and March 2021 at our department. The medical records of the patients were reviewed, and demographic data, clinical characteristics, histological type, treatment outcomes, and complications were analyzed. Results: The surgical energy devices used were LigaSure ${ }^{\circledR}$ in the first 4 cases, Acrosurg ${ }^{\circledR}$. Scissors S17 in the next 13 cases, and Acrosurg ${ }^{\circledR}$. Revo S15 in the latest 7 cases. The operation time (range: 72-250 min; mean: $147 \mathrm{~min}$ ), intraoperative blood loss (range: 5-370 mL; mean: $33 \mathrm{~mL}$ ), indwelling time of wound drain (range: 2-6
\end{abstract}

karger@karger.com www.karger.com/bmh

Karger $\stackrel{\text { ' }}{5}$
(C) 2021 The Author(s)

Published by S. Karger AG, Basel

This is an Open Access article licensed under the Creative Common Attribution-NonCommercial-4.0 International License (CC BY-NC) (http://www.karger.com/Services/OpenAccessLicense), applicable to the online version of the article only. Usage and distribution for commercial purposes requires written permission. days; mean: 3.5 days), and hospitalization period (range: 3-8 days; mean: 5.5 days) were within acceptable ranges. In this study, it is suggested that Acrosurg ${ }^{\circledR}$. Revo $\mathrm{S} 15$ can shorten the indwelling time and the hospitalization period. There were no serious complications, but 1 patient developed transient vocal cord paralysis, which improved 3 months after surgery. It was suggested that the microwave energy devices, Acrosurg ${ }^{\circledR}$. Scissors S17 and Acrosurg ${ }^{\circledR}$. Revo S15, may be more effective with respect to sealing/hemostasis/ coagulation capacity and controllability than the high-frequency electrosurgical device, LigaSure ${ }^{\circledR}$. Conclusion: Based on this initial experience, VAT using surgical energy devices appeared to be a safe, effective, and minimally invasive procedure for the treatment of thyroid/parathyroid tumors. Further studies confirming these early findings are needed.

(c) 2021 The Author(s).

Published by S. Karger AG, Basel

\section{Introduction}

Remarkable technological innovations have been taking place in the field of surgical treatment. Trends have now shifted toward less-invasive procedures irrespective of the organs involved, and endoscopy-assisted 
surgery has been rapidly adopted. In Japan, endoscopic surgery was introduced for thyroid surgery in 1998 [1, 2] and was approved for coverage under the Japanese public health insurance system in 2016, spurring its nationwide spread. Today, video-assisted thyroidectomy (VAT) is no longer considered an unusual surgery. There are mainly 2 different procedures for endoscopic thyroid surgery: one is to make a small incision directly in the cervical region and operate the inside under endoscopic assistance. The other is to make a small incision outside the cervical region, most commonly the subclavicular region, and operate the thyroid under endoscopic assistance. We performed the latter procedure. The skin incision was $2.5 \mathrm{~cm}$ in length at $7 \mathrm{~cm}$ from the midline. After lifting the skin flap, a trocar was inserted through a $5-\mathrm{mm}$ skin incision in the lower neck. Then, an endoscope was set through the trocar, and surgery was performed under a video monitor using an energy device.

With the rapid spread of endoscopic surgery, various energy devices have been developed or modified to facilitate the surgical procedure. We introduced VAT in our department in 2018. Over the subsequent 3 years, we have been using surgical energy devices and obtained favorable treatment outcomes with few postoperative complications. We herein summarize the cases we have experienced so far and review the points that should be considered when introducing VAT as a new surgical procedure, along with the characteristics of the surgical energy devices.

\section{Subjects and Methods}

Three preparatory steps were required pursuant to the 2018 introduction of VAT at our department: (1) training of our surgeons by a supervisory doctor at a certified institution, (2) applying for approval as a newly accredited facility by the Regional Bureau of Health and Welfare, and (3) obtaining approval from the intrahospital Medical Safety Committee. The last of these steps was the most labor intensive. From the viewpoint of medical safety, strict attention was paid to safety management as in any medical practice. Repeated discussions and rehearsals were held by operating staffs, including surgeons, anesthesiologists, and nurses, to secure medical safety.

We performed VAT in 24 patients with thyroid/parathyroid tumors from the introduction of this surgery to March 2021. They comprised 14 women and 10 men, aged $24-83$ years, with a mean age of 59.0 years. The medical records of the patients were reviewed, and demographic data, clinical characteristics, histological type, treatment outcomes, and complications were analyzed. The surgical energy devices we used were a vessel sealing system (LigaSure ${ }^{\circledR}$; Covidien Japan, Tokyo, Japan), a microwave scalpel (Acro- surg. ${ }^{\circledR}$ Scissors S17; Nikkiso Co., Tokyo, Japan), and its upgraded model (Acrosurg. ${ }^{\circledR}$ Revo S15; Nikkiso Co.). Three different surgeons performed VATs in the present study.

\section{Results}

Table 1 shows the characteristics of the patients. The affected side was the right side in 11 patients, the left side in 7 patients, and the isthmus in 6 patients. The extension of thyroidectomy was lobectomy in 16 patients, isthmusectomy in 6 patients, and parathyroidectomy in 2 patients. The histopathological type was adenomatous goiter in 7 patients, cyst in 6 patients, follicular adenoma in 4 patients, papillary carcinoma in 3 patients, parathyroid adenoma in 2 patients, and follicular carcinoma in 1 patient. Complementary thyroidectomy before radioactive iodine ablation was performed in the remaining 1 patient (patient No. 2). Although some of the tumors were fairly big, all of them could be pulled out through the $2.5 \mathrm{~cm}$ subclavicular incision because of the plasticity and elasticity of both tumors and skin.

We used LigaSure ${ }^{\circledR}$ in the first 4 cases, but changed the device to Acrosurg. ${ }^{\circledR}$ Scissors S17 in the next 13 cases because of its better efficiency and controllability. In the 7 most recent cases, we adopted the higher efficiency model, Acrosurg. ${ }^{\circledR}$ Revo S15. The operation time was $72-250$ min (mean: $144.7 \mathrm{~min}$ ). The intraoperative blood loss was 5-370 mL (mean: $31.2 \mathrm{~mL}$ ). The indwelling time of wound drain was 2-6 days (mean: 3.5 days). The hospitalization period was 3-8 days (mean: 5.5 days). There was no significant difference in the operation time and the intraoperative blood loss between the Acrosurg. ${ }^{\circledR}$ Revo group and the other devices group; however, in the Acrosurg. ${ }^{\circledR}$ Revo group, the indwelling time and the hospitalization period were significantly decreased in this study. The indwelling time of the Acrosurg. ${ }^{\circledR}$ Revo $S 15$ group (mean: 2.7 days) was significantly shorter than that of the other devices group (mean: 3.8 days) (Fig. 1). The hospitalization period of the Acrosurg. ${ }^{\circledR}$ Revo S15 group (mean: 4.3 days) was significantly shorter than that of the other devices group (mean: 5.9 days) (Fig. 1).

Results were expressed as mean \pm SEM. Statistical comparisons were performed with Student's $t$ test. Analysis of variance for multiple comparisons was used. In these cases, $p<0.05\left(^{*}\right)$ was considered significant. Although there were no serious complications, such as permanent paralysis of the recurrent laryngeal nerve or postoperative hemorrhage, 1 patient developed transient vocal cord paralysis, which improved 3 months after surgery (patient No. 19). 


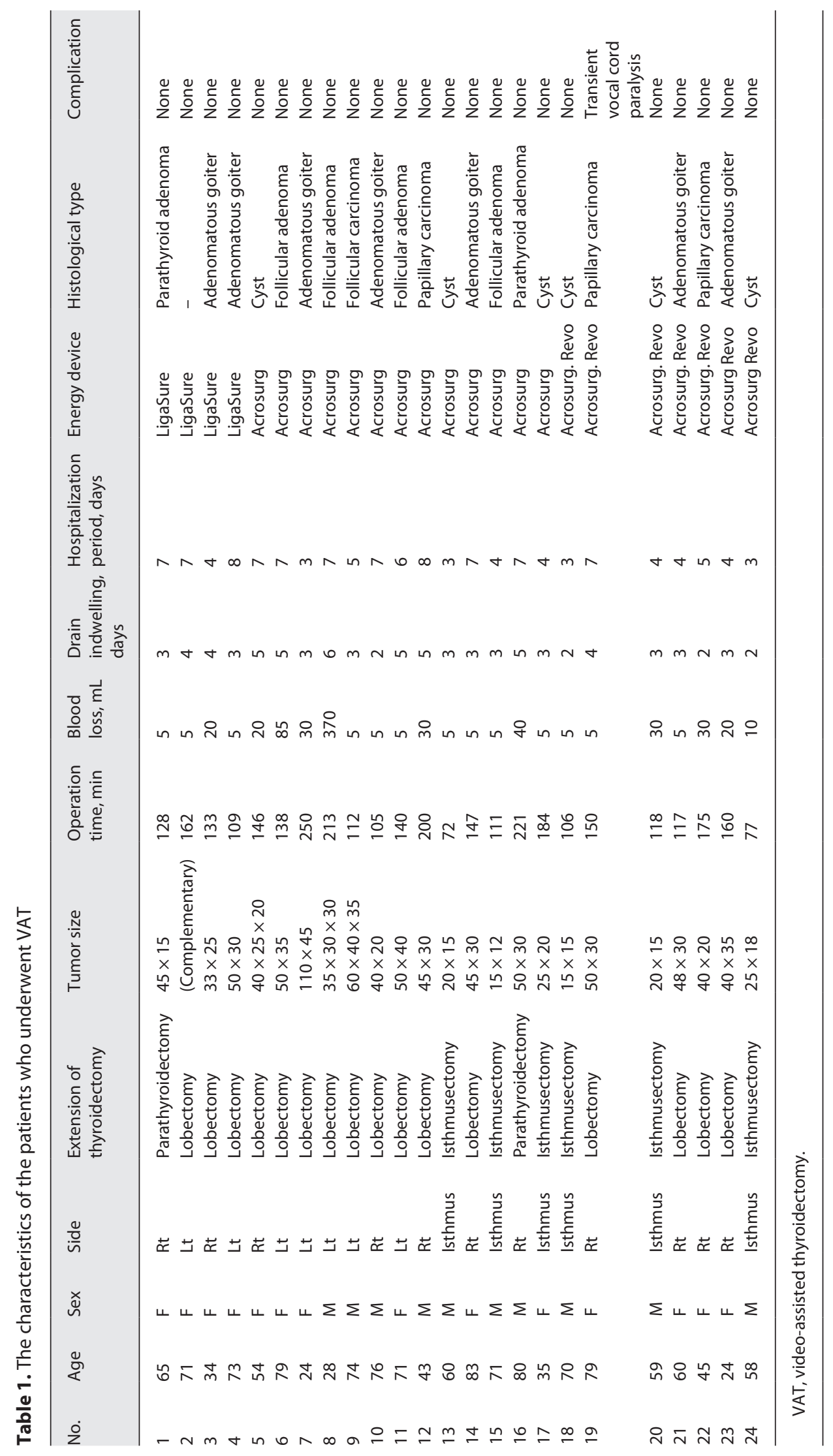


Fig. 1. The indwelling time of wound drain and the hospitalization period. The indwelling time of the Acrosurg. ${ }^{\circledR}$ Revo S15 group $(N=7)$ (mean: $2.7 \pm 0.29$ days) was significantly shorter than that of the other devices group (LigaSure and AcroSurg S17, $N=17$ ) (mean: $3.8 \pm 0.27$ days). The hospitalization period of the Acrosurg. ${ }^{\circledR}$ Revo S15 group $(N=7)$ (mean: $4.3 \pm 0.52$ days) was significantly shorter than that of the other devices group (LigaSure and AcroSurg. $S 17, N=17$ ) (mean: $5.9 \pm 0.42$ days).

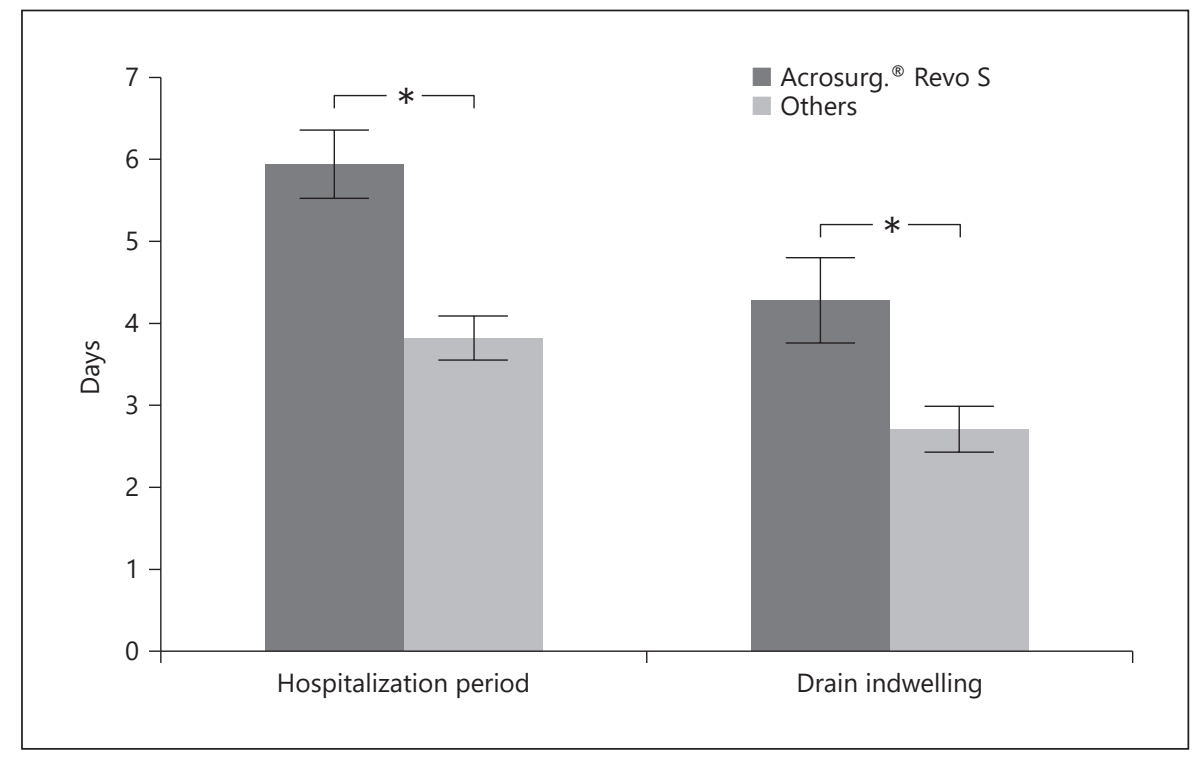

\section{Discussion}

Endoscopic thyroidectomy was first attempted 20 years ago, but it took more than a decade to reach a consensus among head and neck surgeons on the practical validity and usefulness of this procedure. Possible reasons for this include the following. First, the procedure requires surgeons to prepare endoscopes and custom-ordered surgical instruments such as muscle hooks and retractors. Second, special training is required to learn the surgical maneuvers. Third, there is an opinion that ordinary thyroidectomy is not a particularly invasive procedure to begin with, and thus does not necessitate the use of an endoscope.

However, previous studies have demonstrated that endoscopic thyroid surgery is a safe and minimally invasive procedure with less bleeding and higher satisfaction of patients [3-5]. Since April 2016, when VAT was first approved for coverage by the Japanese public health insurance system, the procedure has grown increasingly popular across Japan and is now no longer considered a rare surgery. Because this surgical procedure enables us to perform thyroidectomy using only a few small skin incisions, each measuring $2.5 \mathrm{~cm}$ in length, in inconspicuous sites such as the subclavicular region, it leaves minimal postoperative scars and is particularly preferred by young women.

On the other hand, the use of only small skin incisions in VAT also carries some serious risks. Namely, it may make it difficult to manage intraoperative and postopera- tive bleeding, and uncontrollable intraoperative bleeding could lead to an accidental injury to the recurrent laryngeal nerve. Moreover, any delay in managing postoperative bleeding could induce airway stenosis/obstruction.

In this sense, surgical energy devices are safe and powerful tools in VAT. Ideally, such devices would meet several requirements, such as high sealing capability, limited heat generation for coagulation, and ease in handling. In the first 4 cases, we tried a high-frequency electrosurgical vessel sealing system, LigaSure ${ }^{\circledR}$, which is widely used in high-volume institutions. In the next 13 cases, we adopted a microwave scalpel (Acrosurg. ${ }^{\circledR}$ ). The microwave scalpel has excellent efficiency and is capable of coagulation, vascular sealing/hemostasis, and dissection in succession by pinching the target tissue between the scissortype blades $[6,7]$. The sealing capacity of this device was suitable for the vascular diameters of the inferior and superior thyroid arteries. With regard to coagulation capacity, microwaves uniformly act on water molecules in the target tissue and minimally cause uneven coagulation, which helps minimize heat generation and tissue charring [8]. Additionally, the blade of the microwave scalpel retains less heat than that of high-frequency devices, thereby preventing the risk of thermal damage to surrounding tissues, such as the recurrent laryngeal nerve.

Mist and smoke generated during tissue coagulation/ dissection can obstruct the surgical view and maneuvers during endoscopic surgery. Compared to ultrasonic devices and high-frequency devices, which produce considerable amounts of mist and smoke, the microwave scalpel 
generates only a small amount of water vapor and provides a clearer view of the surgical field [6-8].

The upgraded model, Acrosurg. ${ }^{\circledR}$ Revo $S$, which we used in the latest 7 cases, has further points of improvement: a reinforced blade hinge, tapered blade tip, $360^{\circ}$ rotation shaft, and slimmer shaft diameter. In this study, it is suggested that Acrosurg. ${ }^{\circledR}$ Revo S can shorten the indwelling time and the hospitalization period. Certainly, there are some limitations in the present study. First, the number of enrolled cases is relatively small. We need to further accumulate VAT cases and improve our surgical skill of this procedure. Second, the better outcome in the latest 5 cases using Acrosurg. ${ }^{\circledR}$ Revo S15 may not be attributed to the high performance of the energy device, but to surgeons' proficiency in the procedure. Third, 3 different surgeons performed 24 VATs in the present study. After accumulating a sufficient number of cases, we must analyze and report therapeutic outcomes in each surgeon separately in a future study. We stress that surgical energy devices, particularly the microwave scalpel, are useful and powerful tools to assist in endoscopic surgical maneuvers such as those in VAT.

\section{Conclusions}

We retrospectively analyzed the treatment outcomes of 24 patients with thyroid/parathyroid tumors who underwent VAT assisted with surgical energy devices. The operation time, intraoperative blood loss, indwelling time of wound drain, and hospitalization period were within acceptable ranges. One patient showed transient vocal cord paralysis, but no major postoperative complications were observed. Based on this initial experience, VAT using surgical energy devices appeared to be a safe, effective, and minimally invasive procedure for the treatment of thyroid/parathyroid tumors. Further studies confirming these early findings are needed.

\section{Acknowledgment}

We thank Dr. Akihiro Katayama, the Director of the Endoscopic Thyroid Surgicenter, Sapporo Tokushukai Hospital, for his professional advice and instruction on the surgical techniques.

\section{Statement of Ethics}

This research was conducted ethically in accordance with the World Medical Association of Helsinki, and informed consent was obtained from all individual participants included in the study and was approved by the Ethics Committee of Medical Research, University of Occupational and Environmental Health, Japan (UOEHCRB20-263).

\section{Conflict of Interest Statement}

All authors approved this manuscript and declare that there are no conflicts of interest.

\section{Funding Sources}

There was no funding source for this study.

\section{Author Contributions}

Jun-ichi Ohkubo contributed to editing the manuscript and analysis of data; Tetsuro Wakasugi, Shoko Takeuchi, Shoichi Hasegawa, and Azusa Takahashi contributed to interpretation of data and drafting the article; Hideaki Suzuki contributed to editing the manuscript and supervision.

\section{Data Availability Statement}

All data generated or analyzed during this study are included in this article. Further enquiries can be directed to the corresponding author.

\section{References}

1 Shimizu K, Akira S, Tanaka S. Video-assisted neck surgery: endoscopic resection of benign thyroid tumor aiming at scarless surgery on the neck. J Surg Oncol. 1998 Nov;69(3):17880.

2 Miccoli P, Berti P, Conte M, Bendinelli C, Marcocci C. Minimally invasive surgery for thyroid small nodules: preliminary report. J Endocrinol Invest. 1999 Dec;22(11):849-51.

3 Miccoli P, Berti P, Raffaelli M, Materazzi G, Baldacci S, Rossi G. Comparison between minimally invasive video-assisted thyroidec- tomy and conventional thyroidectomy: a prospective randomized study. Surgery. 2001 Dec;130(6):1039-43.

4 Lombardi CP, Raffaelli M, Princi P, Lulli P, Rossi ED, Fadda G, et al. Safety of video-assisted thyroidectomy versus conventional surgery. Head Neck. 2005 Jan;27(1):58-64.

5 Dobrinja C, Trevisan G, Makovac P, Liguori G. Minimally invasive video-assisted thyroidectomy compared with conventional thyroidectomy in a general surgery department. Surg Endosc. 2009 Oct;23(10):2263-7.
6 Takebayashi K, Shiomi H, Naka S, Murayama $\mathrm{H}$, Murakami K, Akabori $\mathrm{H}$, et al. Utility of a microwave surgical instrument in sealing lymphatic vessels. Am J Surg. 2013 Aug; 206(2):229-33.

7 Ulmer BC. The hazards of surgical smoke. AORN J. 2008 Apr;87(4):735-8.

8 Vinh NQ, Tani T, Naka S, Yamada A, Murakami $\mathrm{K}$. Thermal tissue change induced by a microwave surgical instrument in a rat hepatectomy model. The Am J Surg. 2016 Jan; 211(1):189-96. 